\title{
Ethical Decision Making in International Business: A Study of Challenge in Teaching to Future Global Talents
}

\author{
Rebecca Chunghee Kim \\ Correspondence: Rebecca Chunghee Kim, College of International Management, Ritsumeikan Asia Pacific University, \\ Beppu, Japan
}

\author{
Received: February 16, 2016 Accepted: March 7, 2016 Online Published: March 17, 2016 \\ doi:10.11114/bms.v2i2.1469 URL: http://dx.doi.org/10.11114/bms.v2i2.1469
}

\begin{abstract}
The importance of ethical decision-making in international business has never been more apparent than in recent years. However, discussion concerning its teaching to future global talents who will be at this stage soon is scant and under-developed. Adapting Rest's (1986) four-component model, the study attempts to sketch a broad outline of ethical decision-making by university students when they face an ethical dilemma. The imaginary story, which the author intentionally designs to analyze ethical decision-making through covering real-world ethical issues in an international market, is used as the main methodological tool. Participants acknowledge 'ideal' ethical decisions according to their own discretion, but their 'actual' decision is different due to the intention (motivation) of individuals as to whether they make ethical decisions. This study demonstrates significant gaps in teaching business ethics and suggests a shift of the teaching focus from enlightenment of moral awareness/judgment to stimulating and motivating to initiate ethical decisions and actions.
\end{abstract}

Keywords: ethical decision-making, ethical dilemma, business ethics teaching, moral intent, moral motivation

\section{Introduction}

Ethical dilemmas in international business are rampant. The reasons for ethical decision-making are various. Many leading international corporations have a code of ethics, ethics officers and other ethical principles, and try to demonstrate their strong stance on ethical issues as a moral enterprise (Bebeau, 2002; Fombrun and Foss, 2004). However, in reality, a number of international firms have been increasingly criticized by the public for their unethical decision-making and misbehavior (Knittel and Stango, 2014; Tenbrunsel, 1998). High impact business scandals (for instance, bribery, child labor and the environment) which continuously occur around the globe are evidence of this oxymoronic situation. In addition, various misinterpretations by business and political leaders are major reasons in relation to unethical decisions (e.g., tobacco executives' addictive properties of nicotine; hospital executives' claims to Medicare; medical professionals' undervaluing mental illness compared to physical illness; top leaders' integrity) (Grover and Hasel, 2015; Tenbrunsel, 1998; Thornicroft, 2011).

In these contradictory situations, teaching global talents on ethical decision-making and how to treat ethical dilemmas in their future is critical and challenging. Although there are questions on teaching ethics in professional schools (e.g., ethics could not be or should not be taught; faculty are ill-equipped to teach ethics; ethics as a part of the "hidden curriculum'; interdisciplinary affairs between moral philosophy, psychology and education), teaching ethics is essential to promote students' moral development and character formation (Bebeau, 2002; Han, 2014). Each student has a different individual and situational background and, hence, different priorities regarding decision-making. Ethical issues and dilemmas emerge from individuals' perceptions and stances on the ethical climate of society, culture and organizational environments (Dickson, Smith, Grojean and Ehrhart, 2001; Jones, Felps and Bigley, 2007). Ethical dilemmas and solutions need to be investigated as a context-dependent phenomenon (Pimentel, Kuntz and Elenkov, 2010). In this sense, teaching ethical decision-making needs to have a holistic approach which covers various issues of society and the complex interactions of individuals.

There is a limit to explain ethical dilemmas. For instance, using Kant's deontology versus Mill's utilitarianism. In Asia, Kim and Moon (2015) argue that ethical foundations have always appeared in business decisions. Confucian ethics in Asia are one of the critical aspects for businesses to respect when they make ethical decisions. This explicitly relates to ethical leadership and the principle of love for fellow human beings that has been integrated into Asians throughout 
history (Yin and Zhang, 2012; Wu and Wokutch, 2015).

Despite this situation, existing research on management education places little emphasis on this comprehensive view. Most educators in professional schools today know the significance of a key goal for business ethics teachers is to help future talents improve their moral reasoning within the context of their profession (Jagger, 2011). The purpose of this article is to contribute to closing this gap through developing a framework that teachers and researchers can use. As an initial attempt to identify the perception and interpretation of future talents on ethical issues, the author creates an 'imaginary story' - an ethical dilemma in international business - and probes students' decision-making on it. By analyzing their narratives, the paper attempts to identify future talents' understanding of moral issues and moral framing in international business, and checks how they decide/react in a future dilemmatic situation. Specifically, ethical decision making for students is moral intent (motivation)-contingent. That is, moral motivation is the most significant trigger for the final moral decision and behavior. The paper suggests implications for business ethics and international management teaching and research, especially on how to decide ethically in a challenging global business phenomenon.

\section{Literature Review}

\subsection{Study of Ethical Decision-making}

An individual's decisions and behavior are important as they have consequences for others (Jones, 1991). Although it is difficult to clearly define whether a certain idea or performance is ethical or unethical (Dubinsky and Loken, 1989; Hunt and Vitell, 1986), an ethical decision is generally interpreted as a choice that is both legally and morally acceptable to the community (Jones, 1991). The ethical and moral stance and perspective of a person is essential for discussion as they are related to society. Especially in recent years, the debate has become more apparent due to high impact scandals of different organizations (business, governments, universities, athletics teams, and religious groups), as examples (Trevino, Weaver and Reynolds, 2006). In other words, no institution is free from critical discussion on unethical issues such as lying, cheating and stealing.

What are the main reasons for ethical decisions? There have been studies on the potential that decisions can be made differently due to different moral positions (Stedham, Yamamura and Beekun, 2007). The reasons for the divergence have been discussed and a significant amount of research has been conducted. For instance, Schweitzer, Ordonez and Douma (2004) describe the significance of a 'goal' by arguing that people with unmet goals are more likely to engage in unethical behavior than individuals attempting to do their best. Existence of a concrete policy (or reward and punishment) and a professional code can be important variables for ethical behavior (Cloward and Ohlin, 1960). Emotions such as guilt and shame can be an important reason to address people's ethical decisions (Eisenberg et al., 1994; Gaudine and Thorne, 2001). Barnett (2011) argues for a different focus on the perception of ethical issues between generations: that is, younger people are more responsive to their peers' input when faced with an ethical dilemma, whereas older individuals regard perceived seriousness as the main criterion. Many unethical decisions stem from a lack of awareness (mindfulness) (Ruedy and Schweitzer, 2011), and misuse of incentives and temptation (Tenbrunsel, 1998). Interestingly, Cohen, Pant and Sharp (2001) suggest that education has a minimal effect on raising awareness of ethical issues by showing similar responses between graduating students and entry level students.

We may foresee various reasons for ethical decision-making based on two categories (i.e., individual and situational factors) and their interactive dynamics (Ford and Richardson, 1994; Trenvino, 1986). The purpose of this article is to examine a holistic outline of ethical decision-making by university students when they face an ethical dilemma. Be careful when reading this study because the issues involved in ethical decision-making are complex. Expecting individual or situational factors to lead in a linear manner to specific business decision-making is naive. In other words, it is expected that simple associations to one factor alone are unreasonable. Therefore, this study uses Rest's Four-component Model as a theoretical lens with which to interpret empirical data.

\subsection{Rest's Four-component Model}

Rest's (1986) Four-component Model is regarded as an effective tool in exploring an individual's ethical decision-making process by addressing, assessing and fostering moral growth (Bebeau, 2002; Rogers, 2002; Thomas, 2002). Rest's model is based on four distinct components: moral awareness, moral judgment, moral intent (motivation) and moral action. Moral awareness is the first stage of ethical decision making. To identify a moral issue is significant since it helps in initial decision-making and, in turn, creates ethical performance (Trevino, et al., 2006). An individual's ethical sensitivity, which refers to his/her ability to identify that decision-making has ethical components (Sparks and Hunt, 1998), is a key issue in the process.

Individual variables include nationality (Lewicki and Robinson, 1998), gender (Ambrose and Schminke, 1999; Robinson, Lewicki, and Donahue, 2000; Schminke and Ambrose, 1997), personal characteristics, such as an individual's concern for self-presentation (Covey, Saladin, \& Killen, 1989), and the person's locus of control (the 
connection between behavior and its outcome) as people who have higher internal locus of control are more likely to take responsibility for their ethical performance and act according to their judgment of what is ethical (Trevino and Youngblood, 1990). Other studies also discussed the complex relationship between ethical behavior and reward/punishment (Ashkanasy, Windsor and Trevino, 2006; Tenbrunsel and Messick, 1999; Trevino and Youngblood, 1990).

Organizational/contextual influence is also a key factor for an individual's ethical decision-making. Perhaps more importantly, situational impact can be used to explain divergent individual decision-making in globalization and localization. For instance, every nation has a unique institutional context, and given that people's decision-making is closely bound to the institutional and situational factors of the nation. There must be a reconsideration of ethical decision-making according to its origin. Even though debates of ethics in Asia tend to follow the development of the West, there are different priorities in nations where norms, values and economic development differ (Welford, 2005). Therefore, an examination of context dynamics is more useful for contemporary ethical decision-making research for reflexive understanding and application of the idea of ethics in international business.

Jones (1991) argues that ethical choices are not simply individual decisions. They are determined by social learning and organizational contexts. The ethical setting of an organization/institution/nation is an important factor in an individual's ethical actions. For instance, overt on-the-job pressure (Robertson and Rymon, 2001), and the attitude of peers (Zey-Ferrell and Ferrell, 1982) influence a person's unethical behavior. Distance (physical, psychological, cultural or social) may affect the way in which people interpret moral issues (Jones, 1991).

After an individual acknowledges an ethical issue, moral judgment is more likely to be followed. It is difficult to explore (and has rarely been investigated) the relationship between moral awareness and moral judgment (Trevino, et al., 2006). However, it is clear that moral judgment tends toward an irreversible sequence as higher stages rely on cognitive capacity that is difficult to obtain in lower levels (Kohlberg, 1969). Kohlberg suggests cognitive moral development is comprised of several stages: The lowest two stages (Level 1) - judgment is made based on concern for obedience to authority and fear of punishment (Stage 1) and relationship (Stage 2). The next two stages (Level 2) are composed of stage 3 when people decide according to others' expectations, or rules or laws (Stage 4). The decisions in the highest stages (Level 3) are more focused on individual determinants on what is right or wrong (Stage 5 and 6). This model is useful to study cross-cultural business ethics and types of moral reasoning (Gielen and Markoulis, 1994). However, it is criticized due to issues of the essence of stage progression (Siegler, 1997) and reliability of a primary data set on verbal self-reports (Schweitzer et al., 2004).

The next phase - Establish moral intent (motivation) - examines the resolution of placing moral concerns over other concerns, and taking moral responsibility for moral outcomes (Jones, 1991; Rest et al., 1999). Beyond moral judgment, a sense of obligation to act (Eisenberg, Huntington, Hutchison and Sowa, 1986) should be considered. In other words, we assess an individual's motivation and reasoning to act in accordance with that judgment. Some studies show that individual reasoning and judgment of individuals cannot always be linked to moral action because there is a possibility to limit moral intention or obligation (Roskies, 2003).

The final stage is moral action. This is of interest in itself (Trevino et al., 2006). Many reasons for moral action can be discussed. Two primary factors influence a person's moral awareness, judgment, motivation and behavior.

This study is designed to not only address various reasons for ethical decision-making, but also investigate the moral reasoning process and how each of the components of the process interact in complex ways. Based on the four components of the process identified by Rest's Model, the study asks specifically: what are the implications of the interactions amongst the four elements on ethical decision making?, and how can these implications, if they exist, inform understanding of ethical decision-making by global talents? In other words, by finding the gaps, the study suggests how the university educates future global students.

\subsection{Teaching of Ethical Decision-making and Research Framework}

How we can teach ethical decision-making to international talents who have different individual characteristics and various contextual backgrounds? This research proposes shifting the teaching focus from suggesting so-called moral judgment (see Bebeau, 2002) which must, for various reasons, be diverse across the world to an approach where a compromise can be reached between an individual's characteristics and the context nature of the dilemma (Pimentel et al., 2010; Bebeau, 2002).

By considering relevance to the analysis, this paper uses Rest's four-component Model. Rest argues that each component is not always linked. In other words, success of awareness does not always denote success of judgment or performance (Jones, 1991). We may expect disconnection of each component due to a special circumstance or reason. These theoretical observations and empirical expectations lead to specific research questions listed below. This paper, 
by using the Rest model, (1) seeks to explore the key factors of ethical decisions made by students and whether these are triggered from awareness of the issues or judgment, or intent (motivation). The major and emerging issues affecting each component are analyzed. (2) Divergent students' actions are investigated. Students have individual characteristics and divergent backgrounds (national/institutional/organizational). Consequently, various suggestions will be made. As a final step, (3) how the four components are related to each other is explored. Is there any matching between 'knowing what to do' and 'doing what you know' (Loh and Wong, 2009)? 'What and why' issues are holistically investigated. In short, the three research questions of the study are:
1) How do students perceive/judge/motivate an ethical decision when they face an ethical dilemma?
2) How do students act?; and
3) How do the four components interact with each other?

The initial research framework in Figure 1 depicts its component parts and the research questions. By using this framework, the study seeks to find the limits of current teaching on ethical decision-making and suggest a new teaching direction.

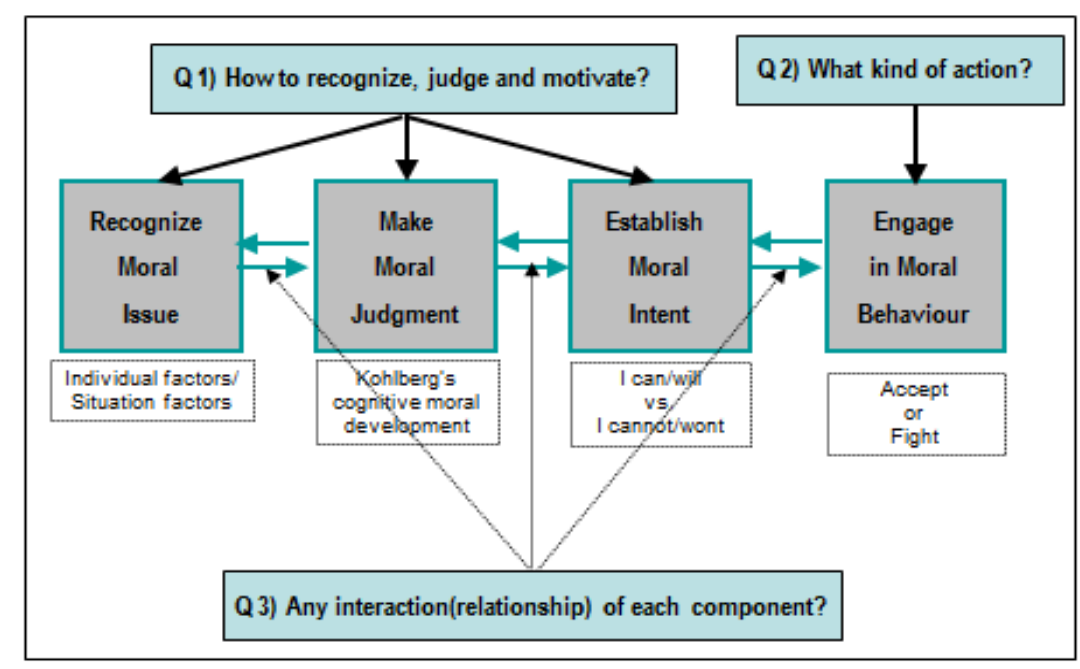

Figure 1. Research Framework of Teaching Ethical Decision-making [based on Rest's Model]

\section{Methodology}

\subsection{Dilemma Based Approach}

Ethical decision-making has been examined from three perspectives (Pimentel et al., 2010). First, a scenario-based approach assesses intent to act in an ethical manner. The main purpose of this approach is to test individual differences such as gender (women report lower intention to behave unethically than men (Valentine and Rittenburg, 2007); older workers show more intention to behave ethically than younger workers when facing an ethical dilemma by suggesting the influence of age and experience in acknowledging the ethical dilemma (Terpstra, Rozell and Robinson, 1993; Valentine and Rittenburg, 2007). The second approach is related to investigation which examines the interaction between moral reasoning and demographic variables in determining ethical behavior. For example, age, gender, and position in an organization are directly associated with research on ethical decision-making.

The third method is the dilemma-based approach that considers the interaction between the content of an ethical dilemma and the decision maker's characteristics. It focuses attention on dilemma characteristics and their moral intensity as determinants of ethical behavior. Due to the expectation that the dilemma is perceived differently because of certain reasons, this study adopts a dilemma-based approach as its methodological direction.

\subsection{Imaginary Story}

An imaginary story (Appendix 1) was designed to cover real-world ethical issues in international business. It was based upon guidelines created throughout the literature review and, in particular, sought to examine students' perception and behavior when faced with a complex ethical dilemma. Based on the research framework proposed in the literature review, the author allowed students to answer freely on their own terms (May, 2001). A flexible approach should help the author to understand the content and context for (analyzing) the results.

Two open-ended questions were asked of participants to answer after they faced the ethical dilemma: (1) What should 
you do?; and, (2) why would you do that? Open-ended questions can be useful in understanding how people feel and think, and surveys and questionnaires are generally less useful (Schein, 1991). This research, therefore, chooses an unrestricted approach to probe students' understanding, judgment, motivation and actions in ethical decision-making. The author's intent was to allow participants to speak candidly and honestly concerning their understanding of the phenomenon, along with various business and non-business related issues, and to remove the possibility of narratives of development being retrospectively imposed on theoretical history by image-conscious informants (Eisenhardt and Graebner, 2007). With this attempt to mitigate bias, the author came to understand the emerging interests and concerns of students in their future ethical decision making.

\subsection{Data Collection and Analysis}

Given the qualitative nature of the data, 60 undergraduate participants were recruited from a Business Ethics Module via class announcement from 2014 to 2015. Because the author's research institution is among the leading global universities in Japan (i.e., Top 30 Global University in Japan selected by the Ministry of Education, Culture, Sports, Science and Technology, Japan), the data sample is ethnically diverse, ranging from Asia (Japan, Korea, China, Indonesia, Vietnam, Thailand, Singapore, Nepal, Mongolia, Sri Lanka, India, Bangladesh), Europe (Germany, Sweden, Poland) and Africa (Kenya), which represent the views of 'international' talents rather than only domestic students. It was assumed that the students participating in this study understood the main ideas and theories concerning ethical decision-making.

Given the large volume of qualitative data derived from students' responses on (1) what should you do?, and (2) why would you do that?, the CAQDAS (computer-assisted qualitative data analysis software) arranged and coded their answers. At the initial stage of analysis, data were coded according to the proposed research framework (Figure 1). NVivo10 was used as a supportive tool to collate the data and look for emergence and interaction of each code efficiently, as shown in Appendix 2. Nvivo allows analysts to create categories and sub-categories, and extract keywords for those categories, and observe the interaction of categories and data (see examples in Appendix 2).

It is assumed that one of the researcher's important responsibilities in this exploratory study is the systematic management of extensive and scattered data, and finding key and emerging issues. That responsibility is closely related to the reliability and validity of the coding process. In contrast to coding quantitative data, coding in qualitative analysis is a method of organizing and managing data in an efficient way (Gibbs, 2002). Therefore, instead of counting and showing the code numbers, the author intends to extract representative and emerging ideas and arguments from the raw data.

\section{Results}

The point of departure for the data analysis in Figure 1 is students' answers in response to the ethical business dilemma. Sixty international undergraduate students between 19-25 years of age were respondents. The study utilized Rest's (1986) Four-component Model to present empirical findings and to identify how students decide upon moral performance and attributes.

Moral awareness: The researcher expected that moral awareness was likely to vary substantially, and the results validated that expectation. This is consistent with Jones' (1991) study that suggested the significance of individual and situational factors for people's ethical decision making. Students seem to understand a paradox that exists in international business. Individual factors are related to their concerns about survival, security and safety, religion, nation, future career and family. A possible explanation is that 'family' is the major concern among individual factors. A Korean student commented:

"This is an unavoidable situation so that I might choose my family because family is the most important value for me." (Korean student, 2014)

Students perceived the situational factor being connected to various issues that included authority, free economy, which is an unavoidable situation, the situation's intensity and procedure and their work role in the situation. Among others, 'work role' is one of the actively discussed subjects for students' awareness of ethical issues:

"There is no way to avoid this situation. You should follow the company's order, otherwise you will be put into the situations as claimed by the author." (Japanese student, 2015)

Moral judgment: For the analysis of moral judgment, the study employs Kohlberg's (1969) idea of cognitive moral development. Students show an overlapping and complex understanding of moral judgment between Levels 1 and 2. In other words, Level 1 (judgment is made based on concerns for obedience to authority and fear of punishment) is frequently used to explain Level 2 perceptions (decide according to others' expectations, rules or laws). "The judgment stems from obedience to my boss" is also closely related to the person's understanding of his/her work role. Therefore, unlike the theoretical discussion, it is difficult to clearly divide the two levels: 
"I have responsibilities to do what I am told. From this point of view I should just follow my instructions and do as I am told even though it does not feel right." (German student, 2015)

A decision at the highest stages (Level 3) is more focused on individual determinants about what is right or wrong. The majority of students choose these reasons for their judgment towards moral identity and against feelings of guilt.

"It is my belief that bribery and corruption are unethical actions, and I would feel very guilty if I follow the instruction leading to bad effects damaging the whole community in ABC land." (Thai student, 2014)

Moral intent (motivation): Interestingly, there is significant understanding by students in this stage - an individual's feeling of limits in (international business) society, and little intention to overstep that boundary. This is due to their perception on negative perspectives towards society and surrounding circumstances. This phenomenon includes students' cynical notions on an unfair world and powerful business, no power as an employee, limits as a foreigner, a free economy, which is unavoidable, and cozy relations between business and politics.

"I don't have much influence or power against the local politicians and police so there is only one person against them, Mr. Mohamed, who has support from the community, gained through providing employment to the people of the community." (Sri Lankan student, 2104)

"Even though many people say "we all have the same human rights", it has been only limited to words or letters." (Indonesian student, 2015)

Of course, an individual's own view on the 'right thing to do' is considered as a major contribution for his/her ethical prudence. Nonetheless, this study found that the majority of students have a notion of individual powerlessness that is a major obstacle for their ethical decisions. In this light, the author suggests further scholarly discussion on this emerging phenomenon.

Moral action: Every individual has different personal characteristics and social (situational) backgrounds that influence his/her decision for ethical action. There are various reasons for individuals to decide whether or not they move toward moral or immoral action, as discussed above. No valid link was found (such as the link between moral awareness, moral judgment, moral intent and moral action). Rather, they overlapped and were complex. Nonetheless, an individual's stance on moral intent strongly influences the decision for moral action. According to their intention, students' preferred actions are diverse and even strategic. Many students discussed fighting corruption by showing firm beliefs. Interestingly, suggested ways of contending with corruption vary. They included: file a report for human rights, resign, stop this vicious cycle and look to the long term, talk to the local CEO, work with a third party (lawyer, government, police, FBI, and use public, NGO, internet and media resources. Students show substantial certainty that they can work together with the third party to fight corruption.

"I would fight with them with all I have got to the end, and not close the company." (Thailand student, 2014)

"The director should consult the problem with the organization that works against bribery and corruption. These organizations are usually very experienced and may help him. It may be also good to report the situation (with the organization's support) to the reliable media." (Poland student, 2015)

Many participants expressed their willingness to accept their employer's order and pursue the acquisition. The reasons are: just follow the employer's order, we have to be selfish, and talk to the boss for a solution.

"If I assume that I will follow his theories about deontological ethics the right choice in this dilemma would be to fulfill my duty for my employer and do my job. And that action would be considered morally right regardless of the consequences of my actions in this case." (Swedish student, 2015)

"Selfish as I may be considered by the outsiders, this should be my decision for the following considerations." (Vietnamese student, 2015)

Interestingly, some students think of alternative actions such as following the company's order first and acting later or telling a lie and leaving the company. Instead of a right or wrong short-term decision, they think of substitute actions by arguing that it is much more strategic and smarter to find (long-term) solutions.

"I will accept to do the thing that I have been instructed to protect my family from going to jail while on other hand I will try to do every possible thing that can be done to save the company like informing NGOs, INGOs and media about the ongoing situation with the help of the local CEO and the workers of the company as I have one year before closing the company." (Nepalese student, 2014)

In summary, the conclusions suggest a significant point of students' feelings of powerlessness aligned with ethical intent (motivation), which indicates a strong relationship between ethical decision-making and performance. In other words, contingent upon ethical intent (motivation), students prefer moral action. 


\section{Discussion and Proposed Framework}

\subsection{Proposed Framework}

The author has attempted to sketch a broad outline of ethical decision-making by future talents when they face an ethical dilemma. Participants understand an 'ideal' ethical decision according to their own values, but their 'actual' decision is different due to the individual's intention (motivation), whether they make an ethical decision or not.

This study demonstrates significant gaps in teaching of ethics at a university. The results suggest that early teaching methods (i.e., the application of theories and principles to resolution) (see Bebeau, 2002) should be revised. In other words, business ethics teaching should transfer the focus from enlightenment of awareness/judgment (either individual or organization-based theories) to how to motivate students to initiate ethical decisions and actions. For example, the focus of teaching should be transformed:

\begin{tabular}{ll}
\hline From & Child labor/bribery is wrong/right according to Kant's Categorical Imperative or Mill's \\
& Utilitarianism? \\
\hline To & How can an individual's decisions create a better environment? \\
& How can an individual change (international) society? \\
& How can an individual make his own ethical decisions over societal pressures?
\end{tabular}

Students show reasonable awareness of ethical issues and ethical judgments although they are divergent in line with individual characteristics and situational factors. However surprisingly, a limit of intention on ethical decision making was found, the major reason being the feeling of powerlessness as an individual due to his/her understanding of the negative perspectives of society.

The results contradict the proposal of Ruedy and Schweizer (2011): people's unethical decisions stem from their mindfulness (awareness). There is limited matching between 'knowing what to do' and 'doing what you know' (Loh and Wong, 2009) because of the lack of intent (motivation). Students argue that "the outcome is not because of me, but because of overall society". The outcome is also related to the question, "What unethical behavior is so rampant in these days?" Students identify this phenomenon in relation to the idea of powerless individuals and the unfair games without rules in international markets. It is beyond the limit of awareness.

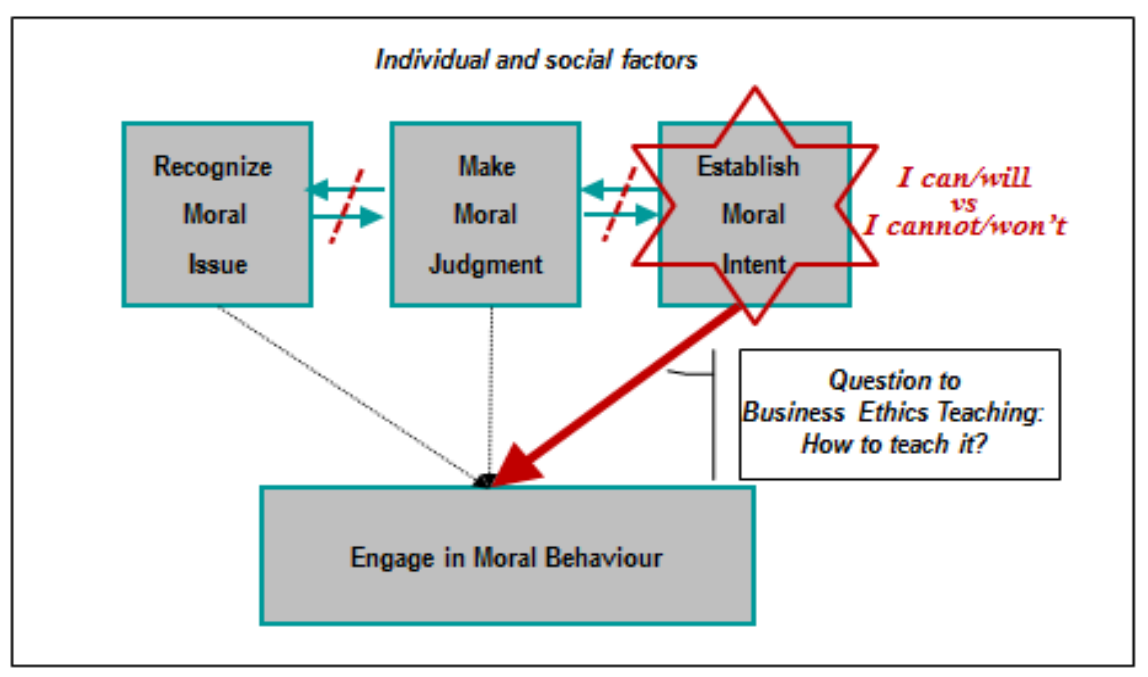

Figure 2. Proposed Framework of Ethical Decision-making of the Future Global Talents

As suggested in Figure 2, the research reveals that the main contributor for students to engage in moral behavior is not the matter of awareness or judgment. Specifically, an individual's establishing of moral intent is much more influential to the final decision and performance. There have been teachings on ethics focused on ethical reasoning and resolving moral issues, but limited teaching and research on how to cope with moral intent and character that is diverse according to one's individual and situational factors. More substantively, little research explicitly discusses "how to teach it". Jagger (2011) argues that a key goal for an ethics teacher is to help future talents [1] improve their moral reasoning [2] within the context of their profession. The article proposes that the first goal is fairly accomplished, but the second goal, 
which is critical for moral development and character formation, is overlooked in the field of teaching business ethics. I suggest that teaching ethical dilemmas cannot be generalized with various theories in a single textbook. In one sense, this paper proposes a "Framework of Ethical Decision Making of Future Talents" (Figure 2).

\subsection{Implication to Ethics Teachers and Further Research}

The proposed framework can be used as a teaching tool in business schools. First, the framework contributes to management and business ethics teaching. Ethics teachers tend to provide a combination of skills-based and rules-based approaches (Jagger, 2011) to promote students' moral development and character formation (Han, 2014). Teachers are concerned with the positive link of awareness and ethical decision-making. However, the framework proposes that an individual's intention towards ethical decisions is more critical to ethical decision-making than moral awareness. Without moral motivation, individuals find it difficult to make proper decisions. The teaching focus should be transformed to facilitate students' intentions instead of urging them to choose between what is right and wrong. That means teaching what is ethical or unethical is not the proper aim of business ethics teaching. Many educators agree that this kind of approach cannot be acceptable in professional schools, especially to mature international students.

Second, the framework proposed in this paper can be used to test the differences between future talents and current businessmen. The context of the paper is limited to a study of university students. By using the same imaginary story in this study (Appendix 1), further research can find differences in motivation and action on ethical decision-making. The main purposes of this study are to explore students' understanding and behavior on ethical decision-making, and to suggest to teachers to offer the possibility of transferability in business ethics teaching. The results of this study can be used for a further test step: is the framework applicable in a real-world situation with international managers? Future research should involve quantitative study with large samples of expatriates, and it will be interesting to observe whether or not the present study's results will be similar with international managers, and whether the reasons that emerge are the same as those emphasized here.

\section{Concluding Remarks}

Can teaching about business ethics be uniform around the globe? The outcome of the present study clearly demonstrates that it cannot. Students in university will have a critical role in international business in the near future. Their ethical decision-making will contribute to the efficient rule of the game in the global market. However, the paper finds the limits of its teaching, and highlights the transformation of the teaching focus: from moral awareness and judgment to facilitation of moral motivation. Since there is no single answer on moral reasoning and judgment, we should refrain from imposing certain universal theoretical constraints on people (Vauclair, 2014) and, rather, encourage people to be motivated by ethical decision-making through teaching about the complexity and dynamics of ethical decision-making. The author hopes that the present work inspires business ethics scholars and teachers to acknowledge the dynamics of business ethics teaching to international students, and advance the framework presented here.

The findings support the arguments of ethical decision models such as Rest (1986) and Jones (1991). However, they do not thoroughly explore how existing students feel concerning the limit of their moral behavior mainly due to various obstacles of current international society. Existing theoretical discussions somewhat ignore the significance of moral intent and dynamic influences for ethical decision-making. The result suggests that teaching of wise understanding of ethical issues and ethical judgment may not be significantly related to facilitating ethical behavior of future talents in international business. Although it would be unwise to discount teaching understanding and judgment of ethical issues, the present study advocates that more care needs to be taken facilitating students' moral motivation and whether or not they may contribute a sustainable development of the global society and, more importantly, the generations to come.

\section{Acknowledgements}

The author would like to thank Thomas Thornborrow for his insights and feedback in developing the imaginary story. Further, the author is grateful to all participants at Ritsumeikan Asia Pacific University (APU) for their very honest and critical sharing of opinions on dealing with ethical dilemmas. The author is solely responsible for any errors and inconsistencies in this paper.

\section{References}

Ashkanasy, N. M., Windsor, C. A., \& Treviño, L. K. (2006). Bad apples in bad barrels revisited: Cognitive moral development, just world beliefs, rewards, and ethical decision making. Business Ethics Quarterly, 16, 449-474. http://www.jstor.org/stable/3857792

Barnett, J. E. (2011). Utilizing technological innovations to enhance psychotherapy supervision, training, and outcomes. Psychotherapy, 48, 103-108. http://dx.doi.org/10.1037/a0023381

Bartlett, D. (2003). Management and business ethics: a critique and integration of ethical decision-making models. 
British Journal of Management, 14, 223-35. http://dx.doi.org/10.1111/1467-8551.00376

Bebeau, M. J. (2002). The Defining Issues Test and the Four Component Model: contributions to professional education. Journal of Moral Education, 31(3), 271-295. http:/www.tandfonline.com/doi/abs/10.1080/0305724022000008115

Cloward, R., \& Ohlin, L. E. (1960). Delinquency and Opportunity - A Theory of Delinquent Gangs. JUSTINFO, NCJ 001783 .

Cohen, J. R., Pant, L. W., \& Sharp, D. J. (2001). An Examination of Differences in Ethical Decision-Making Between Canadian Business Students and Accounting Professionals. Journal of Business Ethics, 30, $319-336$. http://dx.doi.org/10.1023/A:1010745425675

Covey, M. K., Saladin, S., \& Killen, P. J. (1989). Self-monitoring, Surveillance, and Incentive Effects on Cheating. Journal of Social Psychology, 129, 673-680. http://dx.doi.org/10.1080/00224545.1989.9713784

Dickson, M. W., Smith, D. B., Grojean, M. W., \& Ehrhart, M (2001). An organizational climate regarding ethics: the outcome of leader values and the practices that reflect them, The Leadership Quarterly, 12, $197-217$. http://dx.doi.org/10.1016/S1048-9843(01)00069-8

Dubinsky, A. L., \& Loken, B. (1989). Analyzing ethical decision making in marketing. Journal of Business Research, 19(2), 83-107. http://dx.doi.org/10.1016/0148-2963(89)90001-5

Eisenberg, N., Fabes, R. A., Murphy, B., Karbon, M., Maszk, P., \& Smith M., et al. (1994). The relations of emotional-ity and regulation to dispositional and situational empathy-related responding. Journal of Personality and Social Psychology, 66, 776-797. http://dx.doi.org/10.1037/0022-3514.66.4.776

Eisenberg, N., Huntington, R., Hutchison, S., \& Sowa, D (1986). Perceived organizational support. Journal of Applied Psychology, 71, 500-507. http://dx.doi.org/10.1037/0021-9010.71.3.500

Eisenhardt, K. M., \& Graebner, M. E. (2007). Theory Building From Cases: Opportunities and Challenges. Academy of Management Journal, 50(1), 25-32. http://dx.doi.org/10.5465/AMJ.2007.24160888

Fombrun, C., \& Foss, C. (2004). Business Ethics: Corporate Responses to Scandal. Corporate Reputation Review, 7(3), 284-288. http://dx.doi.org/10.1057/palgrave.crr.1540226

Ford, R. C., \& Richardson, W. D. (1994). Ethical Decision Making: A Review of the Empirical Literature. Journal of Business Ethics, 13, 205-221. http://dx.doi.org/10.1007/BF02074820

Gaudine, A., \& Thorne, L. (2001). Emotion and ethical decision-making in organizations. Journal of Business Ethics, 31(2), 175-187. http://dx.doi.org/10.2307/25074527

Gibbs, G. R. (2002). Qualitative Data Analysis: Exploration with NVivo. Buckingham, Philadelphia: Open University Press.

Gielen, U. P., \& Markoulis, D. C. (1994). Preference for principled moral reasoning: A developmental and cross-cultural perspective. In L. L. Adler \& U. P. Gielen (Eds.), Cross cultural topics in psychology, 73-87. Westport, CT: Greenwood.

Grover, S. L., \& Hasel, M. C. (2015). How Leaders Recover (or Not) from Publicized Sex Scandals. Journal of Business Ethics, 129, 177-194. http://dx.doi.org/10.1007/s10551-014-2146-3

Han, H. (2014). Analyzing theoretical frameworks of moral education through Lakatos's philosophy of science. Journal of Moral Education, 43(1), 32-53. http://dx.doi.org/10.1080/03057240.2014.893422

Hunt, S. D., \& Vitell, S. (1986). A general theory of marketing ethics. Journal of Macromarketing, 6(1), 5-16. http://dx.doi.org/10.1177/0276146706290923

Jagger, S. (2011). Ethical Sensitivity: A Foundation for Moral Judgment. Journal of Business Ethics Education, 8, 13-30. http://dx.doi.org/10.5840/jbee2011813

Jones, T. M. (1991). Ethical Decision Making by Individuals in Organizations: An Issue-Contingent Model, Academy of Management Review, 16(2), 366-395. http://www.jstor.org/stable/258867

Jones, T. M., Felps, W., \& Bigley, G. A. (2007). Ethical theory and stakeholder-related decisions: the role of stakeholder culture. Academy of Management Review, 32(1), 137-155. http://dx.doi.org/10.5465/AMR.2007.23463924

Kim, R. C., \& Moon, J. (2015). Dynamics of Corporate Social Responsibility in Asia: Knowledge and Norms. Asian Business \& Management, 14, 349-382. http://dx.doi.org/10.1057/abm.2015.15

Knittel, R. C., \& Stango, V. (2014). Celebrity Endorsements: Firm Value, and Reputation Risk: Evidence from the 
Tiger Woods Scandal. Management Science, 60(1), 21-37. http://dx.doi.org/10.1287/mnsc.2013.1749

Kohlberg, L. (1969). Stage and sequence: The cognitive developmental approach to socialization. In D. Goslin (Ed.), Handbook of socialization theory and research. Chicago: Rand McNally.

Loh, C. Y., \& Wong, J. B. (2009). Matching the 'Knowing what to do' and the 'Doing What You Know' in Ethical Decision-Making. The Australian Accounting Business and Finance Journal, 3(2), 36-47. http://ro.uow.edu.au/aabfj/vol3/iss2/3

May, T. (2001). Social Research: Issues, methods and process. Buckingham: Open University Press.

Pimentel, J. R. C., Kuntz, J. R., \& Elenkov, D. S. (2010). Ethical decision-making: an integrative model for business practice, European Business Review, 22(4), 359-376. http://dx.doi.org/10.1108/09555341011056159

Rest, J. R. (1986). Moral Development: Advances in research and theory. New York: Praeger. http://dx.doi.org/10.1002/1099-1379(200009)21:6<649::AID-JOB45>3.0.CO;2-\#

Rest, J., Narvaez, D., Bebeau, M. J., \& Thoma, S. J. (1999). Postconventional moral thinking: A neo-Kohlbergian approach. Mahwah, NJ: Erlbaum.

Robertson, D. C., \& Rymon, T. (2001). Purchasing agents' deceptive behavior: A randomized response technique study. Business Ethics Quarterly, 11(3), 455-479. http://www.jstor.org/stable/3857849

Robinson, R. J., Lewicki, R. J., \& Donahue, E. M. (2000). Extending and testing a five factor model of ethical and unethical bargaining tactics: Introducing the SINS scale. Journal of Organizational Behavior, 21, 649-664. http://dx.doi.org/10.1002/1099-1379(200009)21:6<649::AID-JOB45>3.0.CO;2-\#

Rogers, G. (2002). Rethinking Moral Growth in College and Beyond. Journal of Moral Education, 31(3), 325-338. $\mathrm{http}: / / w w w . t a n d f o n l i n e . c o m / d o i / a b s / 10.1080 / 0305724022000008142$

Roskies, A. (2003). Are ethical judgments intrinsically motivational? Lessons from "acquired sociopathy." Philosophical Psychology, 16(1), 51-66. http://dx.doi.org/10.1080/0951508032000067743

Roy, J., Lewicki, R. J., \& Robinson, R. J. (1998). Ethical and Unethical Bargaining Tactics: An Empirical Study. Journal of Business Ethics, 17(6), 665-682. http://dx.doi.org/10.1023/A:1005719122519

Ruedy, N. E., \& Schweizer, M. E. (2011). In the Moment: The Effect of Mindfulness on Ethical Decision Making. Journal of Business Ethics, 95, 73-87. http://dx.doi.org/10.1007/s10551-011-0796-y

Schein, E. H. (1991). What Is Culture? In P. J. Frost, L. F. Moore, M. R. Louis, C. C. Lundberg \& J. Martin (Eds.), Reframing Organizational Culture. London: Sage Publications.

Schminke, M., \& Ambrose, M. L. (1997). Asymmetric perceptions of ethical frameworks of men and women in business and nonbusiness settings. Journal of Business Ethics, 16(7), 719-729. http://dx.doi.org/10.1023/A:1017953626566

Schweitzer, M. E., Ordóñez, L., \& Douma, B. (2004). Goal setting as a motivator of unethical behavior. Academy of Management Journal, 47(3), 422-432. http://www.jstor.org/stable/20159591

Siegler, R. S. (1997). Concepts and methods for studying cognitive change. In change and development: Issues of theory, method and application. In E. Amsel \& K. A. Renninger (Eds.). 77-98. Mahwah, NJ: Lawrence Erlbaum.

Sparks, J. R., \& Hunt, S.D. (1998). Marketing researcher ethical sensitivity: Conceptualization, measurement, and exploratory investigation. Journal of Marketing, 62, 92-109. http://dx.doi.org/10.2307/1252163

Stedham, Y., Yamamura, J. H., \& Beekun, R. I. (2007). Gender differences in business ethics: justice and relativist perspectives. Business Ethics: A European Review, 16(2), 163-174. http://dx.doi.org/10.1111/j.1467-8608.2007.00486.x

Tenbrunsel, A. E. (1998). Misinterpretation and Expectations of Misrepresentation in an Ethical Dilemma: The Role of Incentives and Temptation. Academy of Management Journal, 41(3), 330-339. http://dx.doi.org/10.2307/256911

Tenbrunsel, A. E., \& Messick, D. M. (1999). Sanctioning systems, decision frames, and cooperation. Administrative Science Quarterly, 44, 684-707. http://dx.doi.org/10.2307/2667052

Terpstra, D. E., Rozell, E., \& Robinson, R. K. (1993). The influence of personality and demographic variables on ethical decisions related to insider trading. Journal of Psychology, 127(4), 375-389. http://dx.doi.org/10.1080/00223980.1993.9915573

Thomas, S. J. (2002). An Overview of the Minnesota Approach to Research in Moral Development. Journal of Moral Education, 31(3), 225-245. http://dx.doi.org/10.1080/0305724022000008098 
Thornicroft, G. (2011). Physical health disparities and mental illness: the scandal of premature mortality. The British Journal of Psychiatry, 199, 441-442. http://dx.doi.org/10.1192/bjp.bp.111.092718

Trenvino, L. K. (1986). Ethical Decision making in Organizations: A Person-Situation Interactionist Model. Academy of Management Review, 11(3), 601-617.

Treviño, L. K., \& Youngblood, S. A. (1990). Bad apples in bad barrels: A causal analysis of ethical decision making behavior. Journal of Applied Psychology, 75(4), 447-476.

Treviño, L. K., Weaver, G. R., \& Reynolds, S. J. (2006). Behavioral Ethics in Organizations: A Review. Journal of Management, 32(6), 951-990. http://dx.doi.org/10.1177/0149206306294258

Valentine, S. R., \& Rittenburg, T. L. (2007). The ethical decision making of men and women executives in international business situations, Journal of Business Ethics, 71, 125-134. http://dx.doi.org/10.1007/s10551-006-9129-y

Vauclair, C. M. (2014). Cultural conceptions of morality: Examining laypeople's associations of moral character. Journal of Moral Education, 43(1), 54-74. http://dx.doi.org/10.1080/03057240.2013.873365

Welford, R. (2005). Corporate Social Responsibility in Europe, North America and Asia: 2004 Survey Results. The Journal of Corporate Citizenship, 17, 33-51. http://dx.doi.org/10.9774/GLEAF.4700.2005.sp.00007

Wu, J., \& Wokutch, R. E. (2015). Confucian stakeholder theory: An exploration. Business and Society Review, 120(1), 1-21. http://dx.doi.org/10.1111/basr.12046

Yin, J., \& Zhang, Y. (2012). Institutional dynamics and corporate social responsibility (CSR) in an emerging country context: Evidence from China. Journal of Business Ethics, 111(2), 301-316. http://dx.doi.org/10.1007/s10551-012-1243-4

Zey-Ferrell, M., \& Ferrell, O. C. (1982). Role-set configuration and opportunity as predictors of unethical behaviour in organizations. Human Relations, 35(7), 587-604. http://dx.doi.org/10.1177/001872678203500707 


\section{[Appendix 1] An Imaginary Story: A moral dilemma}

You have just been appointed as the Finance Director for Asia of a large multinational bank (the Bank of Northeastern States), based in the United States and headquartered in Boston, Massachusetts. You have been posted to a recent acquisition of a Stock Market listed manufacturing plant, Peninsula Transport located in a small township some 40 kilometers outside the capital city of ABC Land (the name of the country in Asia). Your instructions are to asset strip the acquired company then close it down within one year.

Two weeks into your appointment and having just arrived in $\mathrm{ABC}$ Land, you are given a company-provided apartment and have spent several days unpacking and settling in with your family. Today is your first day at work and Mr Mohamed, the incumbent CEO a man who has inherited the company from his father informs you that he knows exactly why you are in ABC Land and begs you not to close his company. As the day progresses, you begin to realize that before the $\$ 100$ million acquisition, the factory had been a wholly owned family business that had served the community for more than four decades and employed just under half the town's available workforce of three thousand people. Indeed, there were many families, some with three generations in current employment with the company. In addition, you also realize that many small and medium local enterprises support the factory and that to close it will devastate the entire community. The CEO claims that he and his family are victims of a conspiracy to close the factory and sell the land to build real estate on it. He shows you a newspaper report from several years ago that clearly depicts the land surrounding the town being earmarked for development under the government's plans for the future of the area. This involves building several thousand residential units and expanding the township into a commuter suburb serving the capital city.

Mr Mohamed informs you that he has rejected several offers from the government and has successfully fought them in the courts and obtained 'heritage status' protection to overturn a local government order for compulsory purchase of the land from his family who have owned it for several generations.

The local CEO also informs you that he has evidence of bribes and gifts being made by the Bank of Northeastern States to local politicians, as well as substantial donations to the National People's Party, a political party which is the incumbent government. It is very clear that there is a trail of corruption leading all the way back to your employers in Boston. That night you call your CEO at Northeastern Bank to inform him and are shocked when he responds with threats against you and your family that if you don't do as instructed you will be arrested and thrown in jail by the local police. The next morning before you leave for work, you are paid a clandestine visit by a senior police officer and he also informs you in a veiled threat that your situation in $\mathrm{ABC}$ Land leaves you and your family very vulnerable. At this point, you realize that you have been lied to by the Board of Northeastern States Bank and that they are partners in a web of corruption worth tens of millions of US Dollars involving ABC land's local politicians and local police.

You find yourself in a dilemma. If you follow through with your instructions you understand that you will be responsible for the social consequences of closing the factory and will be just as guilty as those who are involved in the conspiracy. If you don't you will be fired and face an uncertain future in which you and your family, having already been threatened, leaves you in no doubt of the consequences of being arrested and detained in a foreign country where you have no rights.

Two questions to answer:

What should you do?

Why would you do that? 


\section{[Appendix 2] The relationships between code and raw data in NVivo 10}

Extract of code list

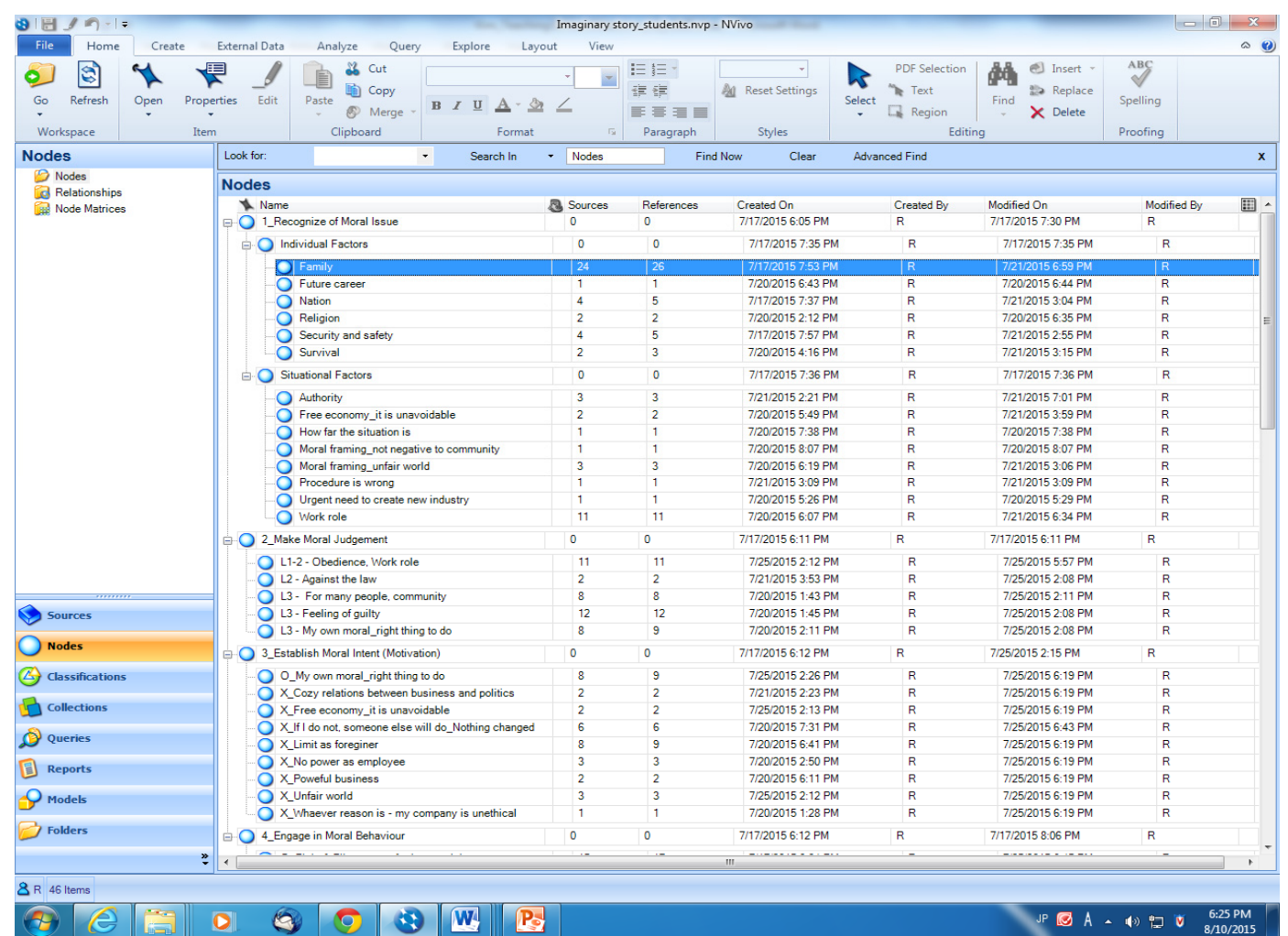

$5 \longrightarrow$ Relationships of code with interview text

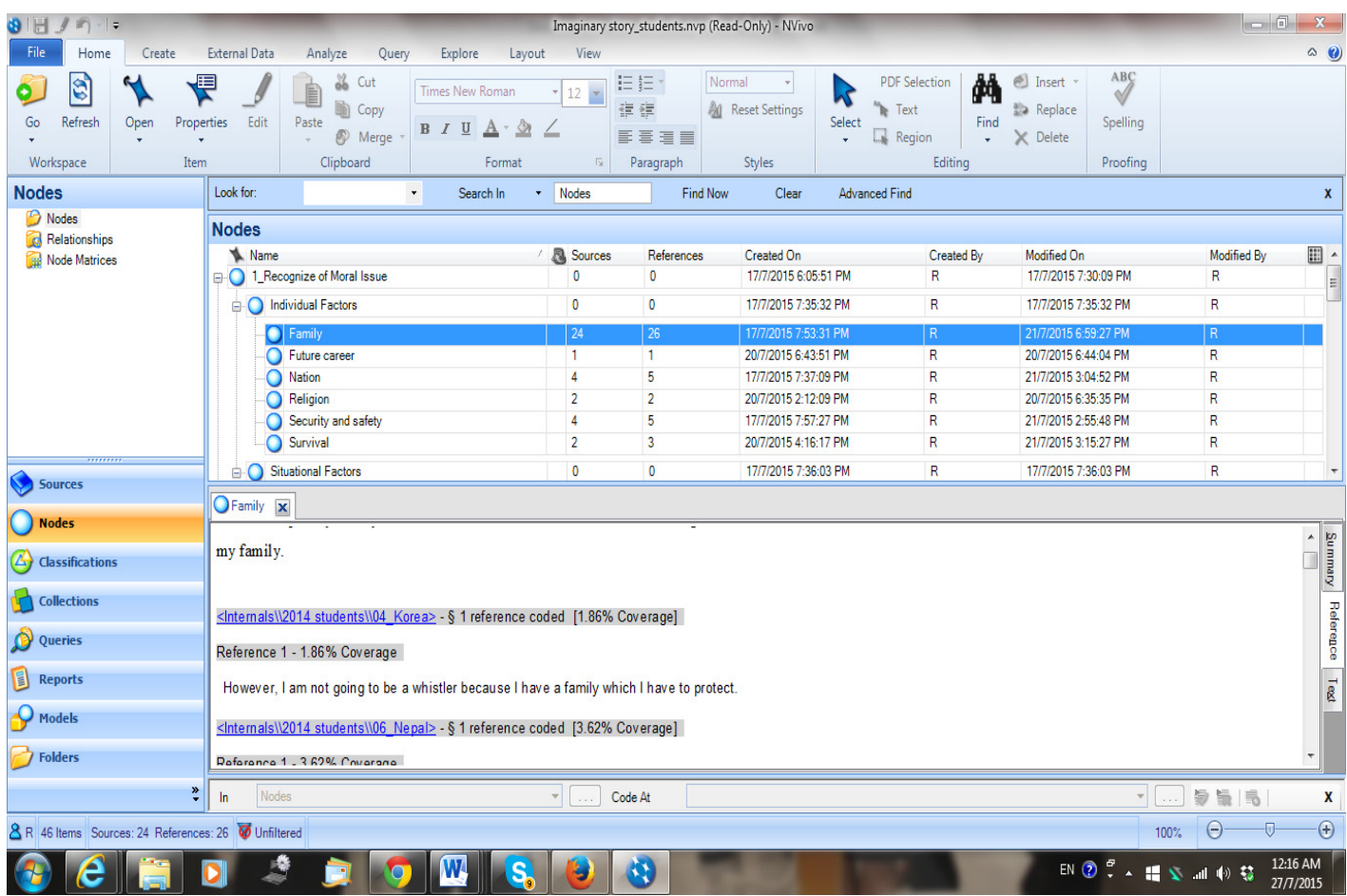

\section{$(\mathrm{cc})$ EY}

This work is licensed under a Creative Commons Attribution 3.0 License. 